\title{
Method to Regenerate Ammonia for the Capture of Carbon Dioxide
}

\author{
Houping Huang and Shih-Ger Chang* \\ Environmental Energy Technology Division \\ Lawrence Berkeley National Laboratory \\ University of California, Berkeley, CA 94720 \\ Thomas Dorchak \\ National Energy Technology Laboratory \\ Morgantown, WV 26507
}

\begin{abstract}
Compared to the conventional MEA process for the capture and separation of carbon dioxide from flue gas, the ammonia scrubbing technique provides several advantages, such as a higher capture efficiency and capacity, lower decomposition temperatures of ammonium bicarbonate, as well as lower costs and less corrosion to absorber material. However, in addition to the highly volatile nature of ammonia, the lack of a method to separate ammonia from $\mathrm{CO}_{2}$ after thermal decomposition of ammonium bicarbonate also hinders the ammonia scrubbing technique from being applied in practice. This paper investigates a method to regenerate ammonia so as to allow for the ammonia scrubbing technique to be practical in the capture of $\mathrm{CO}_{2}$. The new method requires the use of weakly basic ion-exchange resins containing amine functional groups. At ambient temperatures, these resins were found to be effective in the regeneration of ammonia from ammonium bicarbonate, which is the main product formed after the absorption of $\mathrm{CO}_{2}$ by ammonia. The resin, which absorbed the carbonic acid, can also be regenerated when it is heated by water at temperatures equal to or greater than $50^{\circ} \mathrm{C}$. Also, through several runs of a resin absorption-desorption experiment, the sustainability of the resin for the regeneration of ammonia from ammonium bicarbonate was evidently demonstrated.
\end{abstract}

\section{Introduction}

The most widely used process for the capture of $\mathrm{CO}_{2}$ is based on chemical absorption with a monoethanolamine (MEA) or diethanolamine (DEA) solvent ${ }^{1-4}$. The process may incorporate inhibitors to resist solvent degradation and equipment corrosion ${ }^{5,6}$. Also, to reduce the corrosion the solvent strength was kept relatively low, resulting in large equipment sizes and high regeneration energy requirements ${ }^{2,6}$. Research of methods to reduce cost in chemical absorption is important for large-scale application such as the sequestration of $\mathrm{CO}_{2}$ from power plants. Finding a low cost solvent that can reduce the equipment size by increasing the absorption efficiency, reduce equipment corrosion, and reduce regeneration temperature after absorption of $\mathrm{CO}_{2}$ is the key. 
With its lower costs, higher capacity and efficiency ${ }^{7}$ for the absorption of carbon dioxide, and the lower decomposition temperatures of ammonium bicarbonate, as well as its being less corrosive to absorber material, the ammonia scrubbing technique possesses many advantages for the capture of carbon dioxide than the conventional MEA process. Currently though, a process to regenerate ammonia from its carbonate salts is lacking, thus rendering the ammonia scrubbing technique impractical.

This paper studied the capability of anion exchange resins to regenerate ammonia from ammonium bicarbonate as well as the feasibility for the regeneration of resin by heated water and a collection of $\mathrm{CO}_{2}$. In essence, the combination of the use of ammonia for the absorption of $\mathrm{CO}_{2}$ and the use of a basic anion exchange resin for the regeneration of ammonia is another dual alkali approach ${ }^{8}$ we are researching to lower the cost for the capture and separation of $\mathrm{CO}_{2}$ from flue gas. The effectiveness of various types of resin to regenerate ammonia from ammonium bicarbonate will be demonstrated. This paper will also test the sustainability of the resin through a series of adsorption-desorption experiments.

\section{Experimental Section}

Materials. The following materials were used: $\mathrm{CO}_{2}\left(8.5 \%\right.$, with $\mathrm{N}_{2}$ as balance, Baygas Co.), Ammonia ( $\mathrm{NH}_{4} \mathrm{OH}, 28-30 \%$, J.T. Baker Inc.), Ammonium Bicarbonate (99+\%), Purolite A-830 (Polyamine, moisture: $50 \%$, weakly basic anion exchange, Purolite Co.), Amberlite IRA-96 (Polyamine, moisture: 60\%, Sigma Co.), Amberlite IRA-67 (Polyamine, moisture: $\sim 60 \%$, Sigma Co.), Supelco WA-30 (Alkylamine, moisture: 49\%, Supelco), Amberlyst A-7 (Amine, moisture: 56\%, Janssen Chimica), Amberlyst A-21 (Tertiary amine, $-\mathrm{N}(\mathrm{CH})_{3}$, moisture: $\sim 57 \%$, Janssen Chimica). The following reagents were prepared for titration: $1 \%$ Phenolphthalein was prepared by dissolving $1.0 \mathrm{~g}$ of phenolphthalein, $90 \mathrm{~mL}$ of ethanol and $10 \mathrm{~mL}$ of de-ionized water. $.1 \%$ Methyl orange solution was prepared by dissolving $.1 \mathrm{~g}$ of methyl orange into 100 $\mathrm{mL}$ of deionized water. $.077 \mathrm{M}$ Hydrochloric acid standard solution was standardized by sodium tetraborate decahydrate.

Absorption of $\mathrm{CO}_{2}$. At a flow rate of $500 \mathrm{~mL} / \mathrm{min}$, a $\mathrm{CO}_{2}(8.5 \%)$ gas was passed through a glass reactor with a sintered bottom containing $25 \mathrm{~mL}$ of an absorbent $(15 \%$ $\mathrm{NH}_{4} \mathrm{OH}$ or the regenerated ammonia solution) to determine $\mathrm{CO}_{2}$ absorption capacity. The temperature was held at $25^{\circ} \mathrm{C}$ with a constant temperature bath (PolyTemp). A cold trap with ice was employed to condense the moisture in the $\mathrm{CO}_{2}$ gas stream that came out of the reactor. The change in the concentration of $\mathrm{CO}_{2}$ with time was monitored by a FTIR spectrometer (Model 1605, Perkin-Elmer Co.) with a 10-cm optical pass gas cell, while the amount of $\mathrm{CO}_{2}$ absorbed was calculated using a concentration vs. time curve.

Regeneration of Ammonia from Ammonium Bicarbonate by Resin. $200 \mathrm{~mL}$ of 1 $\mathrm{M}$ ammonium bicarbonate solution was added to a water-jacketed reactor. Before the addition of a resin, the initial $\mathrm{pH}$ of the solution was measured using a digital $\mathrm{pH}$ meter with a combination electrode. $50 \mathrm{~g}$ (containing 40-60\% moisture) of resin was then washed by $200 \mathrm{~mL}$ of de-ionized water. The resin was filtered and the water was 
discarded. The washed resin was later transferred to the reactor to initiate the adsorption reaction for the regeneration of ammonia. The mixture was stirred at a constant rate of $800 \mathrm{rpm}$. The temperature was held constant at $25^{\circ} \mathrm{C}$. To trace the kinetic process of the reaction between a resin and ammonium bicarbonate, five samples were taken for analysis, each one lasting 15 minutes longer than the previous one $(0,15,30,45$, and 60 minutes after reaction). Before each sample was taken, the stirring was stopped. $2 \mathrm{~mL}$ of the liquid was then obtained by a pipette and transferred to a $250 \mathrm{~mL}$ Erlenmeyer flask. The stirring was resumed to continue the reaction after each sample was taken. While the reaction in the reactor was proceeding, each sample was analyzed through titration ${ }^{9}$. For titration, a certain volume of de-ionized water was added to the sample in the $250 \mathrm{~mL}$ Erlenmeyer flask to make up $25 \mathrm{~mL}$ of solution, and 1 drop of phenolphthalein was also added as the first equivalent point indicator. The solution was titrated using hydrochloric acid until it became colorless thus indicating the solution having reached the first equivalent point of the titration. The volume of the $\mathrm{HCl}$ solution consumed was recorded as $\mathrm{V}_{1}(\mathrm{~mL})$. After one hour, the reaction was terminated. Besides the $2 \mathrm{~mL}$ of liquid taken as a sample and analyzed to obtain the concentration of the released ammonia and the total concentration of ammonium, the digital $\mathrm{pH}$ meter also measured the final $\mathrm{pH}$ of the bulk solution in the reactor.

The concentration of ammonia regenerated in the solution by the resin was calculated based on Eq.1.

$\left[\mathrm{NH}_{4} \mathrm{OH}\right]=\left(\mathrm{N}_{\mathrm{HCl}} \mathrm{V}_{1}\right) / \mathrm{V}_{\mathrm{s}}(\mathrm{M})$

Where $\mathrm{N}_{\mathrm{HCl}}$ is the concentration of the standard $\mathrm{HCl}(\mathrm{M}) . \mathrm{V}_{\mathrm{s}}$ is the volume of each sample $(\mathrm{mL}) .\left[\mathrm{NH}_{4} \mathrm{OH}\right]$ is the concentration $(\mathrm{M})$ of ammonia released by a resin in the reaction with ammonium bicarbonate, including not only the concentration of free ammonia but also the concentration of ammonia that had been regenerated by the resin and then reacted with ammonium bicarbonate to form ammonium carbonate. $\left[\mathrm{NH}_{4} \mathrm{OH}\right]$ is equal to the concentration of $\mathrm{H}_{2} \mathrm{CO}_{3}$ adsorbed by the resin from bicarbonate.

The ammonia regeneration efficiency (ARE) of a resin was defined as the amount (mg) of ammonia regenerated by $1 \mathrm{~g}$ (on the dry weight basis) of a resin. The value was estimated according to Eq. 2:

$\mathrm{ARE}=\left(\left[\mathrm{NH}_{4} \mathrm{OH}\right] \mathrm{V} \mathrm{M}_{\mathrm{NH} 3}\right) /\left[\mathrm{W}_{\text {Resin }}(1-\%\right.$ Moisture $\left.)\right] \quad(\mathrm{mg} / \mathrm{g})$

Where $\left[\mathrm{NH}_{4} \mathrm{OH}\right], \mathrm{V}, \mathrm{M}_{\mathrm{NH} 3}$, and $\mathrm{W}_{\text {Resin }}$ are the concentration of ammonia regenerated by the resin (M) after one hour of reaction, the volume of ammonium bicarbonate solution $(\mathrm{mL})$, the molecular formula weight $(\mathrm{g} / \mathrm{mole})$ of ammonia, and the weight $(\mathrm{g})$ of the resin with moisture, respectively.

Following the same procedure stated as above, six kinds of resin, including A-830, IRA-67, IRA-96, WA-30, A-7, and A-21 were investigated. The kinetic curves for the reactions between each of these resins were obtained by plotting the concentration of released ammonia against the reaction time, as shown in Figure 4. The ammonia 
regeneration efficiencies of various resins were summarized in Table 1, as will be discussed later.

To examine the effect of ammonium bicarbonate on the ammonia regeneration efficiency of resin, $50 \mathrm{~mL}$ of $0.1,0.5,1.0,1.5 \mathrm{M}$ ammonium bicarbonate solutions were employed to react with $50 \mathrm{~g}$ of IRA-67 with moisture. The mixture was stirred at a speed of $800 \mathrm{rpm}$. The temperature was controlled at $25^{\circ} \mathrm{C}$. After 15 minutes, the reaction reached its equilibrium and was terminated. Two $\mathrm{mL}$ of sample from the reactor was taken to determine the concentration of the released ammonia by the titration method. The ARE was also estimated according to Eq.2. The results for the dependence of ammonia regeneration efficiency on ammonium bicarbonate concentrations are shown in Figure 2 .

The effect of the ratio of resin amount to ammonium bicarbonate volume on the ammonia regeneration efficiency of a resin was also studied by experiment. Under constant stirring at $800 \mathrm{rpm}$ and a temperature of $25^{\circ} \mathrm{C}, 50 \mathrm{~g}$ (wet) of IRA-67 was employed to react with $70,120,170,220,300 \mathrm{~mL}$ of $1 \mathrm{M}$ ammonium bicarbonate. For each run, the reaction was ended as it reached its equilibrium after 15 minutes, and then 2 $\mathrm{mL}$ of liquid was taken for analysis to obtain released ammonia data by titration. The ARE was finally calculated based on Eq.2. The relationship between ammonia regeneration efficiency and the ratio of the resin amount to ammonium bicarbonate volume is depicted in Figure 3.

Recovery of Resin and Collection of Carbon Dioxide. De-ionized water at various temperatures was studied for its effectiveness to regenerate the resin, which was believed to have adsorbed carbonic acid in the regeneration of ammonia, the $\mathrm{CO}_{2}$-bearing absorbent. The resin and de-ionized water were mixed in a $500 \mathrm{~mL}$ Erlenmeyer flask. The solution was stirred constantly at a speed of $800 \mathrm{rpm}$ and heated up to 50, 80, and $100^{\circ} \mathrm{C}$, respectively. A condenser connected to the flask prevented the water in the mixture from evaporating and separated gaseous $\mathrm{CO}_{2}$ from moisture. The $\mathrm{CO}_{2}$ was released by bubbling $\mathrm{N}_{2}$ gas through the reactor at a flow rate of $100 \mathrm{~mL} / \mathrm{min}$. The $\mathrm{CO}_{2}$ coming out of the reactor was then passed through a container with $100 \mathrm{~mL}$ of $\mathrm{NaOH}$ (1 M) solution to convert the $\mathrm{CO}_{2}$ into carbonate for the determination of the total amount of $\mathrm{CO}_{2}$. The concentration of carbonate in the $\mathrm{NaOH}(1 \mathrm{M})$ solution was determined by the titration of $1 \mathrm{~mL}$ of the sample solution.

The titration was performed as described above for the first equivalent point. After the first equivalent point was achieved, the $\mathrm{HCl}$ standard solution volume used was recorded as $\mathrm{V}_{1} \mathrm{~mL}$. Then, one drop of .1\% methyl orange solution was added to the remaining solution as an indicator for the second equivalent point, and the solution was titrated from green yellow to slight orange red with the addition of hydrochloric acid. The orange-red was an indication that the solution had reached its second equivalent point. The reading of the $\mathrm{HCl}$ solution consumed was recorded as $\mathrm{V}_{2}(\mathrm{~mL})$. With the presence of an excessive amount of $\mathrm{NaOH}$, the original sample contained both $\mathrm{NaOH}$ and $\mathrm{Na}_{2} \mathrm{CO}_{3}$. When the sample was titrated by the addition of $\mathrm{HCl}$ to the first equivalent point, $\mathrm{NaOH}$ was converted into $\mathrm{NaCl}$ and $\mathrm{H}_{2} \mathrm{O}$, while $\mathrm{Na}_{2} \mathrm{CO}_{3}$ was transformed into 
$\mathrm{NaCl}$ and $\mathrm{NaHCO}_{3}$. From first equivalent point to second equivalent point, the amount of $\mathrm{HCl}$ was consumed to titrate $\mathrm{NaHCO}_{3}$ to $\mathrm{NaCl}$ and $\mathrm{H}_{2} \mathrm{CO}_{3}$. The concentration of $\mathrm{Na}_{2} \mathrm{CO}_{3}$ is equal to that of $\mathrm{NaHCO}_{3}$, which was calculated as Eq.3.

$$
\left[\mathrm{HCO}_{3}{ }^{-}\right]=\mathrm{N}_{\mathrm{HCl}}\left(\mathrm{V}_{2}-\mathrm{V}_{1}\right) \quad(\mathrm{M})
$$

The amount of $\mathrm{CO}_{2}$ absorbed in the $\mathrm{NaOH}$ solution, i.e., the emitted $\mathrm{CO}_{2}$ amount from the reaction, can be calculated as follows:

$\left.\mathrm{W}_{\mathrm{CO}_{2}=\left[\mathrm{HCO}_{3}\right]}\right] \mathrm{V}_{\mathrm{NaOH}} \mathrm{M}_{\mathrm{CO} 2}(\mathrm{mg})$

Where $\mathrm{W}_{\mathrm{CO} 2}, \mathrm{~V}_{\mathrm{NaOH}}$, and $\mathrm{M}_{\mathrm{CO} 2}$ are the emitted $\mathrm{CO}_{2}$ amount $(\mathrm{mg})$, the volume of $\mathrm{NaOH}$ absorption solution $(\mathrm{mL})$, and the molecular formula weight of $\mathrm{CO}_{2}(\mathrm{~g} / \mathrm{mole})$, respectively.

By measuring the change of the emitted $\mathrm{CO}_{2}$ with the desorption reaction time, the dependence of the emitted $\mathrm{CO}_{2}$ on the reaction time at various temperatures was obtained (Figure 5).

The Sustainability of Resin for Ammonia Regeneration and Its Recycling. Several cycles were run to examine the sustainability of resin for the regeneration of ammonia and itself with collection of $\mathrm{CO}_{2} .50 \mathrm{~g}$ (wet) IRA-67 was employed to react with $200 \mathrm{~mL}$ of $1 \mathrm{M}$ ammonium bicarbonate in a water-jacked reactor at room temperature. The mixture was stirred as a stirring speed of $800 \mathrm{rpm}$. After reaction for 15 minutes, $2 \mathrm{~mL}$ of liquid was removed from the reactor for the analysis of released ammonia by titration as previously stated, thus obtaining the ARE value the resin. Subsequently, the mixture was filtered, and the liquid was discarded. The resin remained in the reactor. To the reactor, $200 \mathrm{~mL}$ of water was added. The mixture was stirred constantly at $800 \mathrm{rpm}$, and brought to a boil. After boiling for one hour, the resin was separated from the water and cooled down to the room temperature by using cold water. The recycled resin was then used to repeat the same operation 5 more times, and to obtain the ARE data for each run. The result for each run is depicted in Figure 7.

\section{Results and Discussion}

It was recently found that an anion exchange resin (Ra) with a free base as a functional group was able to adsorb $\mathrm{H}_{2} \mathrm{CO}_{3}$ from a $\mathrm{NH}_{4} \mathrm{HCO}_{3}$ solution resulting in the liberation of ammonia at room temperatures (Eq. 5). The resin could then be recycled by the use of water at temperatures equal to or greater than $80^{\circ} \mathrm{C}$ along with the collection of $\mathrm{CO}_{2}$ (Eq. 6)

$\mathrm{NH}_{4} \mathrm{HCO}_{3}+\mathrm{Ra} \leftrightarrow \mathrm{Ra} \bullet \mathrm{H}_{2} \mathrm{CO}_{3}+\mathrm{NH}_{3}$

$\mathrm{Ra} \bullet \mathrm{H}_{2} \mathrm{CO}_{3} \leftrightarrow \mathrm{Ra}+\mathrm{CO}_{2} \uparrow+\mathrm{H}_{2} \mathrm{O}$ 
Regeneration of Ammonia by Resin. Due to the reaction between ammonia and $\mathrm{CO}_{2}$, ammonium bicarbonate is formed. If the ammonia scrubbing technique is to be applied, it is crucial to be able to regenerate ammonia from ammonium bicarbonate. Recently, it was discovered that a weakly basic anion-exchange resin was able to regenerate ammonia from ammonium bicarbonate. To demonstrate this capability of resin, an ammonia solution ( $\mathrm{pH}=13.0)$ was first used to capture $\mathrm{CO}_{2}$ from simulated flue gas $\left(8.5 \% \mathrm{CO}_{2}\right.$ with $\mathrm{N}_{2}$ as the balance) until it could not absorb any more $\mathrm{CO}_{2}$, i.e., the ammonia solution became saturated by $\mathrm{CO}_{2}$, as depicted in Figure 1. The saturated ammonia solution ( $\mathrm{pH}=9.1$ ), most of which should be ammonium bicarbonate, was then passed through a column containing a resin (A-830) at an ambient temperature of $25^{\circ} \mathrm{C}$. After the solution passed through the column with the resin, the $\mathrm{pH}$ of the solution was increased to 11.2. Subsequently, the resultant solution was recycled to absorb $\mathrm{CO}_{2}$ from the simulated flue gas. The absorption curve of $\mathrm{CO}_{2}$ by the recycled ammonia solution was also recorded and shown in Figure 1. It is evident that the recycled ammonia is able to absorb $\mathrm{CO}_{2}$, indicating the "dead" saturated ammonia solution became "alive" after passing through the column with the resin. The amount of $\mathrm{CO}_{2}$ absorbed by the solution was estimated by an integration method, and found to be $38 \%$ of the amount of $\mathrm{CO}_{2}$ absorbed by the original ammonia solution.

The capability of the weakly basic anion-exchange of resins to regenerate ammonia from ammonium bicarbonate is attributed to the reaction of ammonium bicarbonate with the resin's amine functional group. The basicity of amine functional group induces the decomposition of ammonium bicarbonate into ammonia and carbonic acid. With the combination of carbonic acid and amine, the ammonia is released into the solution, resulting in an increase in $\mathrm{pH}$ (Eq. 7).

$\mathrm{R}-\mathrm{NH}_{2}($ or $=\mathrm{NH}$, or $\equiv \mathrm{N})+\mathrm{NH}_{4} \mathrm{HCO}_{3} \leftrightarrow \mathrm{R}-\mathrm{NH}_{2}($ or $=\mathrm{NH}$, or $\equiv \mathrm{N}) \bullet \mathrm{H}_{2} \mathrm{CO}_{3}+\mathrm{NH}_{3}$

The released ammonia will react somewhat with ammonium bicarbonate to form ammonium carbonate, which results in resin's inability to completely regenerate ammonia. Therefore, the regenerated ammonium solution should contain ammonia and ammonium carbonate. Both ammonia and ammonium carbonate are ready to absorb $\mathrm{CO}_{2}$ (Eq. $8 \& 9$ )

$$
\begin{aligned}
& \mathrm{CO}_{2}+\mathrm{NH}_{3}+\mathrm{H}_{2} \mathrm{O} \leftrightarrow \mathrm{NH}_{4} \mathrm{HCO}_{3} \\
& \mathrm{CO}_{2}+\left(\mathrm{NH}_{4}\right)_{2} \mathrm{CO}_{3}+\mathrm{H}_{2} \mathrm{O} \leftrightarrow 2 \mathrm{NH}_{4} \mathrm{HCO}_{3}
\end{aligned}
$$

Further experimentation found that other kinds of resin, besides A-830, were also able to regenerate ammonia from ammonium bicarbonate. The experiments involved mixing a resin with an ammonium bicarbonate solution in a water-jacketed reactor by stirring the mixtures at $25^{\circ} \mathrm{C}$. The $\mathrm{pH}$ of each ammonium bicarbonate solution was 8.2. However, the pHs of the solutions were increased to 9.8, 9.7, 9.4, 9.1, 9.0, and 8.9 after each solution reacted for one hour with A-830, IRA-67, IRA-96, WA-30, A-7, and A-21, respectively. The ammonia regeneration capability of a resin was estimated by dividing the amount of regenerated ammonia by the amount of employed resin on the dry weight 
basis. The results for the ammonia regeneration capability of various resins are shown in Table 1. These results show that all types of weakly basic anion-exchange resin have, to an extent, the ability to regenerate ammonia from ammonium bicarbonate, while A-830 and IRA-67 have capabilities in regenerating ammonia much greater than IRA-96, A-7, A-21, and WA-30. The reason for these results is probably due to the different composition of the amine functional group in various resins. For A-380 and IRA-67, the content of primary and secondary amines is greater than that of other resins, resulting in more ammonia being produced from ammonium bicarbonate.

Table 1. Comparison of ammonia regeneration efficiency of various resins.

\begin{tabular}{|c|c|}
\hline Resin & $\begin{array}{c}\text { Regeneration capability } \\
\text { (mg ammonia/g resin) }\end{array}$ \\
\hline IRA-67 & 47.3 \\
\hline A-830 & 38.8 \\
\hline IRA-96 & 18.4 \\
\hline WA-30 & 12.4 \\
\hline A-7 & 8.5 \\
\hline A-21 & 6.8 \\
\hline
\end{tabular}

The concentration of ammonium bicarbonate solution affects the regeneration efficiency of ammonia. As shown in Figure 2, when the ratio of resin (IRA-67) to the volume of ammonium bicarbonate is kept unchanged, the ammonia regeneration efficiency increases with the concentration of ammonium bicarbonate increasing. When the concentration of ammonium bicarbonate is .1 M, the ammonia regeneration efficiency is only $2.4 \mathrm{mg}$ of ammonia per gram of resin. However, when the concentration of ammonium bicarbonate increases to $1.5 \mathrm{M}$, the ammonia regeneration efficiency increases to $26.1 \mathrm{mg}$ of ammonia per gram of resin. Obviously, more $\mathrm{CO}_{2}$ will be captured by a higher concentration of regenerated ammonia solution than by a lower concentration of regenerated ammonia solution at the same solution volume.

In addition to the concentration, the ratio of resin amount to the volume of ammonium bicarbonate solution also influences the regeneration efficiency of ammonia. When the concentration of ammonium bicarbonate solution is kept the same, the regeneration efficiency of ammonia decreases with an increase in the ratio of resin (IRA67) amount to the volume of ammonium bicarbonate solution, as shown in Figure 3. When the ratio of resin amount to the volume of ammonium bicarbonate is $.07(\mathrm{~g} / \mathrm{mL})$, the ammonia regeneration efficiency is $60 \mathrm{mg} / \mathrm{g}$. However, when the ratio of resin to the volume of ammonium bicarbonate solution increases to $.28(\mathrm{~g} / \mathrm{mL})$, the regeneration efficiency of ammonia becomes $30 \mathrm{mg} / \mathrm{g}$, which is a half of that with the ratio of .07 .

Moreover, the reaction of resin with ammonium bicarbonate is fairly fast. Figure 4 shows the typical kinetic curves of ammonia regeneration by several different types of 
resin. It is apparent that each reaction between resin and ammonium reaches its equilibrium within 15 minutes. The kinetic characters with the reactions are to be investigated in more details.

Recycling of Resin and Collection of Carbon Dioxide. It is essential to find a costeffective way to recycle the resin, which had been used to adsorb carbonic acid in the regeneration of ammonia. It was found that water possesses the ability to regenerate the resin by heating the used resin to temperatures at or above $50^{\circ} \mathrm{C}$. However, the higher the temperature, the more effective the regeneration is. The higher the temperature, the better the regeneration efficiency will be. Along with regenerating the resin, $\mathrm{CO}_{2}$ can also be collected after the water vapor is separated by condensation. To demonstrate the feasibility of this process, we studied the release of $\mathrm{CO}_{2}$ from resin (IRA-67) at different temperatures. The results are shown in Figure 5. Only $13.3 \%$ of the total amount of $\mathrm{CO}_{2}$ absorbed were released at temperatures lower than $50^{\circ} \mathrm{C}$. As the temperature increased, the amount of $\mathrm{CO}_{2}$ released increased as well. When the temperature was kept constant at $80^{\circ} \mathrm{C}$, the desorption reached its equilibrium after one hour. The emitted $\mathrm{CO}_{2}$ was $90 \%$ of the total amount of $\mathrm{CO}_{2}$ absorbed. When the temperature increased to $100^{\circ} \mathrm{C}$, the desorption reached its equilibrium in 15 minutes.

The effect the ratio of resin to the volume of water had on the desorption of $\mathrm{CO}_{2}$ from resin was investigated. As shown in Figure 6, the emitted $\mathrm{CO}_{2}$ from each desorption experiment remained unchanged when the ratio of the amount of resin to the volume of water was raised from .08 to $.25 \mathrm{~g} / \mathrm{mL}$. Thus, to save energy from being used to heat extraneous amounts of water, the ratio of resin to the volume of water should be as large as possible.

The Sustainability of Resin. The sustainability of a resin for the regeneration of ammonia was also demonstrated by several continuously running adsorption-desorption cycles. Figure 7 depicts the ammonia regeneration capability of the resin at each operation. The results indicate that the ammonia regeneration capability of the recycled resin can be repeatedly kept at $87 \%$ of the original resin's capability.

\section{Conclusion}

The current study demonstrates that it is feasible for a resin with a free amine functional group to regenerate ammonia from ammonium bicarbonate at ambient temperatures. It was also found that the regeneration of the resin by heating to $50^{\circ} \mathrm{C}$ or higher with the collection of $\mathrm{CO}_{2}$ was possible. The resin proved to be sustainable as well, so as to be regenerated for repeated uses in the process of regenerating ammonia for the capture of $\mathrm{CO}_{2}$. The results of this study indicate that the thermal energy requirement is much less in a dual alkali system using ammonia to absorb $\mathrm{CO}_{2}$ and anion exchange resins to regenerate ammonia for reuse than using amine to absorb $\mathrm{CO}_{2}$ and steam stripping to dissociate carbamates. 
Acknowledgement. This work was supported by the Assistant Secretary for Fossil Energy, U.S. Department of Energy, under Contract DE-AC03-76SF0098 through the National Energy Technology Laboratory.

\section{References}

1. Buzek, J; Podkanski, J; Warmuzinski, K. The Enhancement of the Rate of Absorption of $\mathrm{CO}_{2}$ in Amine Solutions Due to the Marangoni Effect, Energy Convers. Mgmt 1997, 38, S69-S74.

2. Chakma, A. $\mathrm{CO}_{2}$ Capture Processes - Opportunities for Improved Energy Efficiencies, Energy Convers. Mgmt 1997, 38, S51-S56.

3. Yeh, J. T.; Pennline, H. W.; Resnik, K. P. Study of $\mathrm{CO}_{2}$ Absorption and Desorption in a Packed Column, The Science of the Total Environment, Energy \& Fuel 2001, 15, 274-278

4. Herzog, H.; Drake, E.; Adams, E. $\mathrm{CO}_{2}$ Capture, Reuse, and Storage Technologies for Mitigating Global Climate Change, DOE Final Report DE-AF-22-96PC01257, January 1997.

5 Erga, O.; Juliussen, O.; Lidal, H. Carbon Dioxide Recovery by Means of Aqueous Amines, Energy Convers. Mgmt 1995, 36, 387-392

6. Mimura, T.; Simayoshi, H.; Suda, T.; Iijima, M.; Mituoka, S. Development of Energy Saving Technology for Flue Gas Carbon Dioxide Recovery in Power Plant by Chemical Absorption Method and Steam System, Energy Convers. Mgmt, 1997, 38, S57-S62

7. Yeh, A. C.; Bai, H. Comparison of Ammonia and Monoethanolamine Solvents to Reduce $\mathrm{CO}_{2}$ Greenhouse Gas Emissions, 1999, 228, 121-133.

8. Huang, H.P.; Shi, Y.; Li, W.; Chang, S.G. Dual Alkali Approaches for the Capture and Separation of $\mathrm{CO}_{2}$, Energy \& Fuel 2001, 15, 263-268.

9. Hou, T.P., Manufacture of Soda with special reference to the ammonia process, a practical treatise; Second edition; American Chemical Society: Hafner Publishing Company, New York and London; 1969, pp485. 
Figure 1. Absorption of $\mathrm{CO}_{2}$ by original and regenerated ammonia (Absorption: $\mathrm{CO}_{2}:$ 8.5\%, $500 \mathrm{ml} / \mathrm{min}$; Ammonia:15\%, $25 \mathrm{ml}$; Temp.:25 $5^{\circ} \mathrm{C}$ Ammonia regeneration: Resin:A-830, $40 \mathrm{~g} ;$ Temp.:25ㅇ)

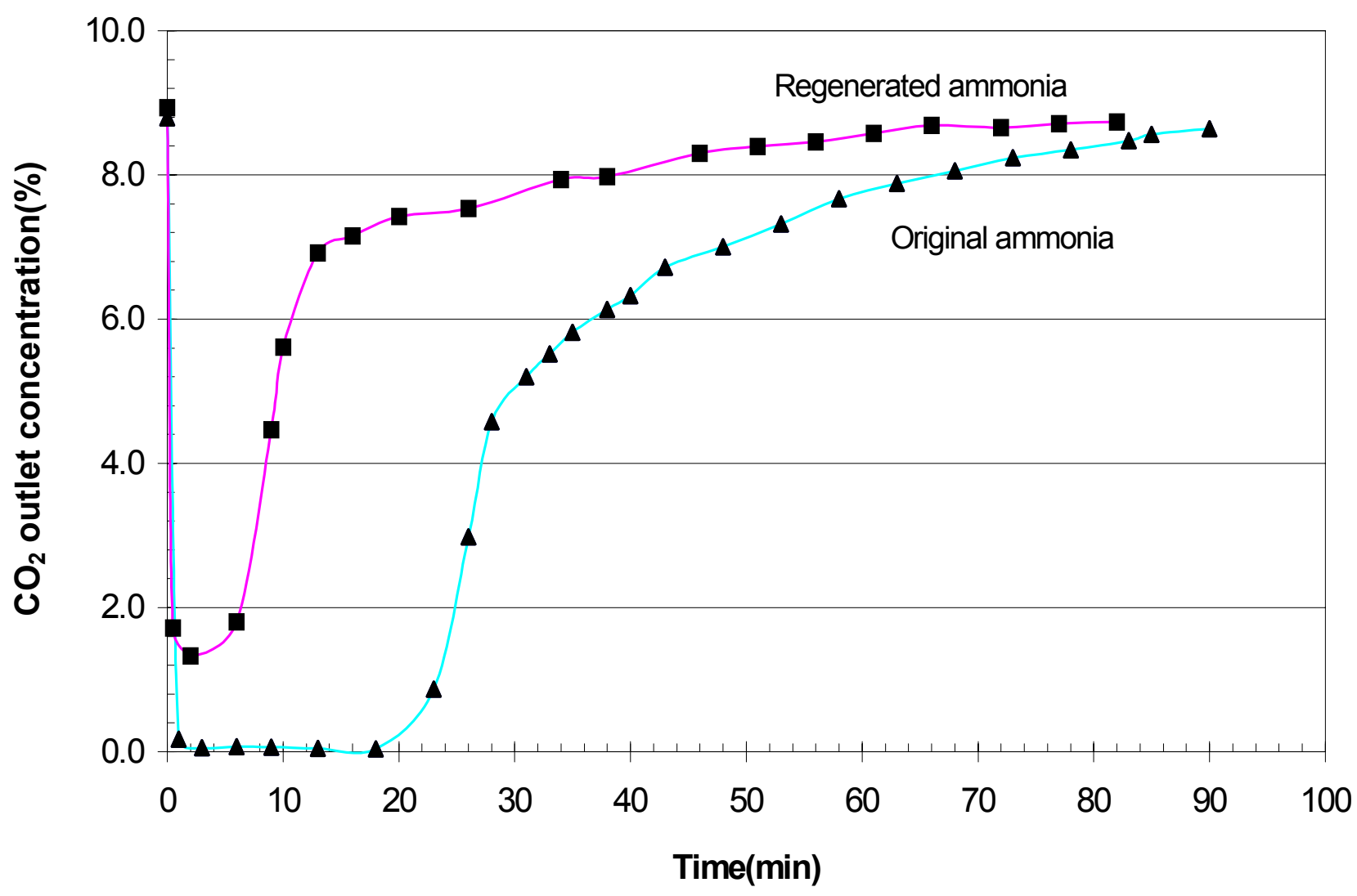


Figure 2. The dependence of ammonia regeneration efficiency on ammonium bicarbonate concentration

(Ammonium bicarbonate: 50ml; Resin: IRA-67,50 g; Stirring speed:800 rpm; Temp.: $25^{\circ} \mathrm{C}$ )

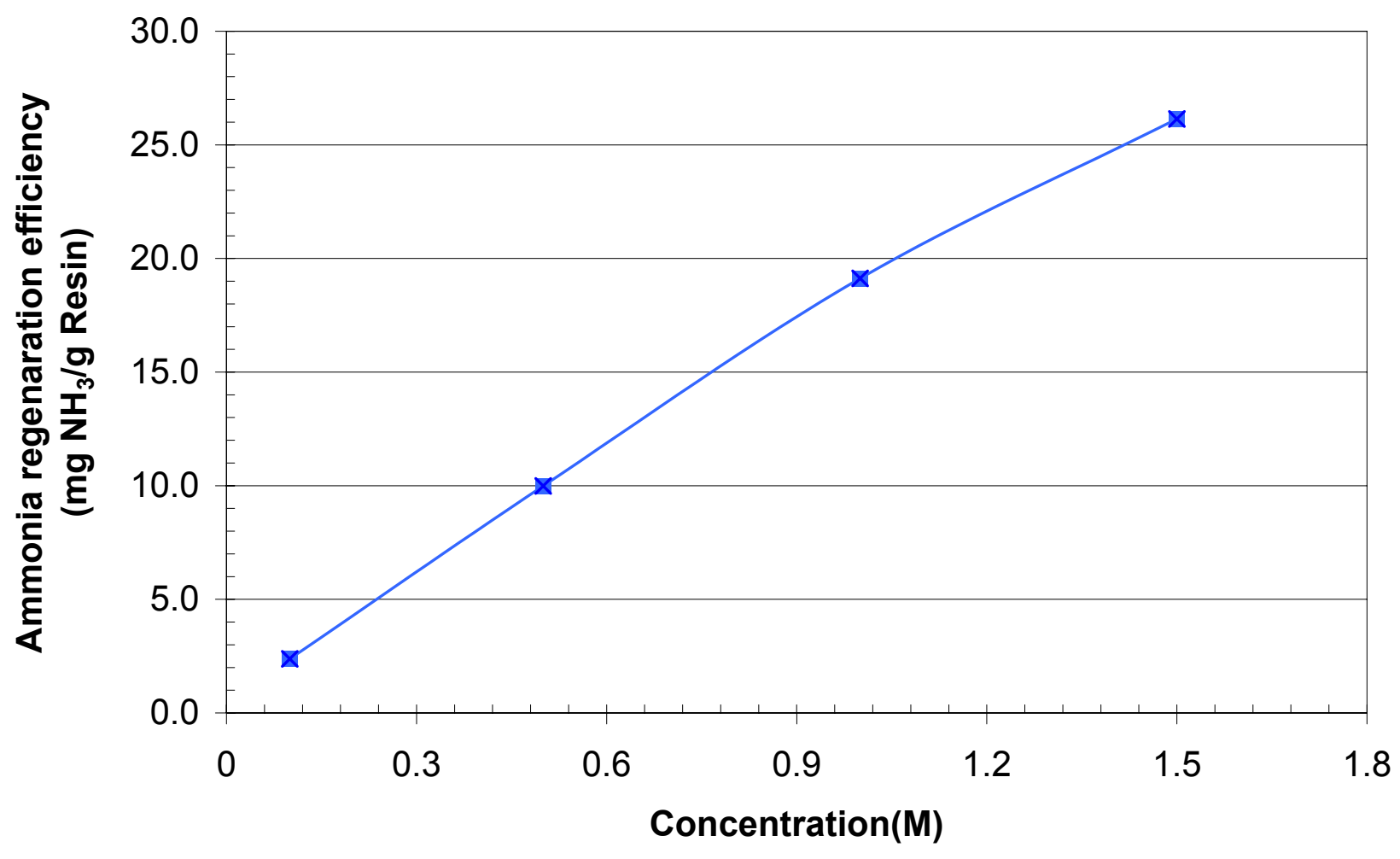


Figure 3. The dependence of ammonia regeneration efficiency on the ratio of resin to ammonium bicarbonate volume

(Ammonium bicarbonate: $1 \mathrm{M}$; Resin: IRA-67, $50 \mathrm{~g}$; Stirring speed:800 rpm; Temp.: $20^{\circ} \mathrm{C}$ )

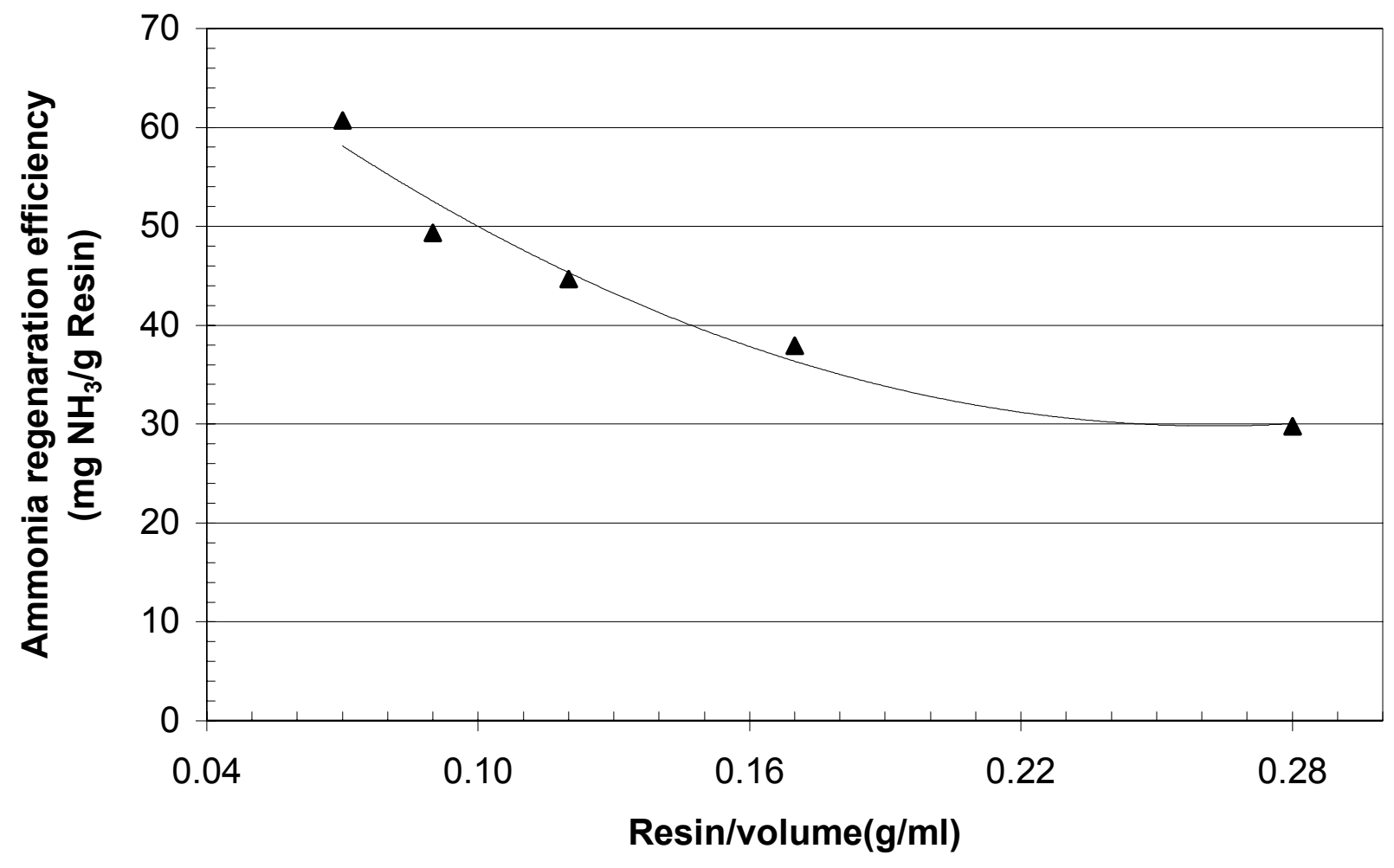


Figure 4. Kinetic curves for the regeneration of ammonia by resin $\left(\mathrm{NH}_{4} \mathrm{HCO}_{3}\right.$ solution: $200 \mathrm{ml}, 1 \mathrm{M}$; Resin: $50 \mathrm{~g}$; Stirring speed: $800 \mathrm{rpm}$; Temp.: $\left.25^{\circ} \mathrm{C}\right)$

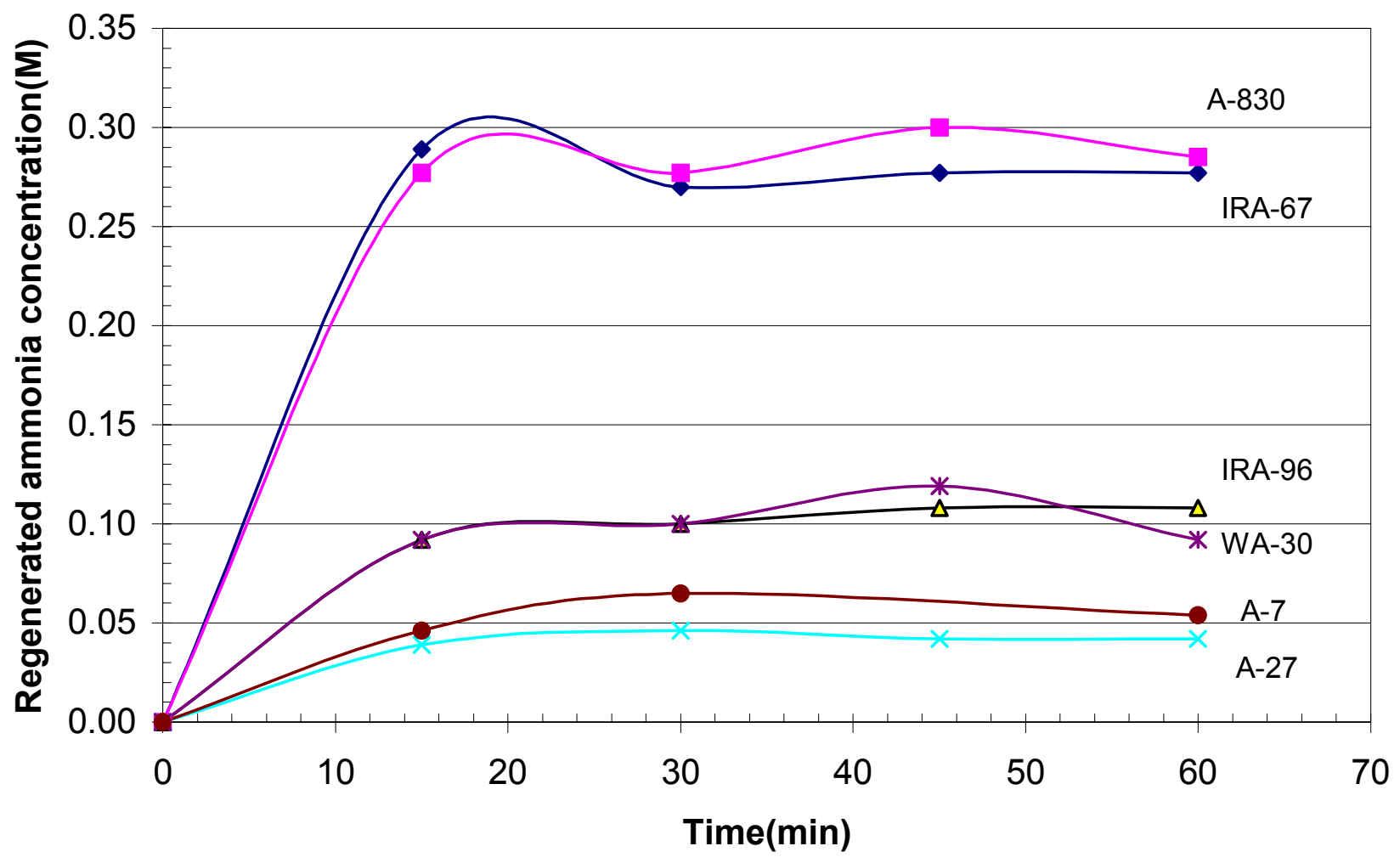


Figure 5. Effect of temperature on the desorption of $\mathrm{CO}_{2}$ and regeneration of resin

(Adsorption:Resin: IRA-67, 50 g; Ammonium bicarbonate: 1M,150 ml; Stirring speed: 800 rpm.; 20 ${ }^{\circ} \mathrm{C}$

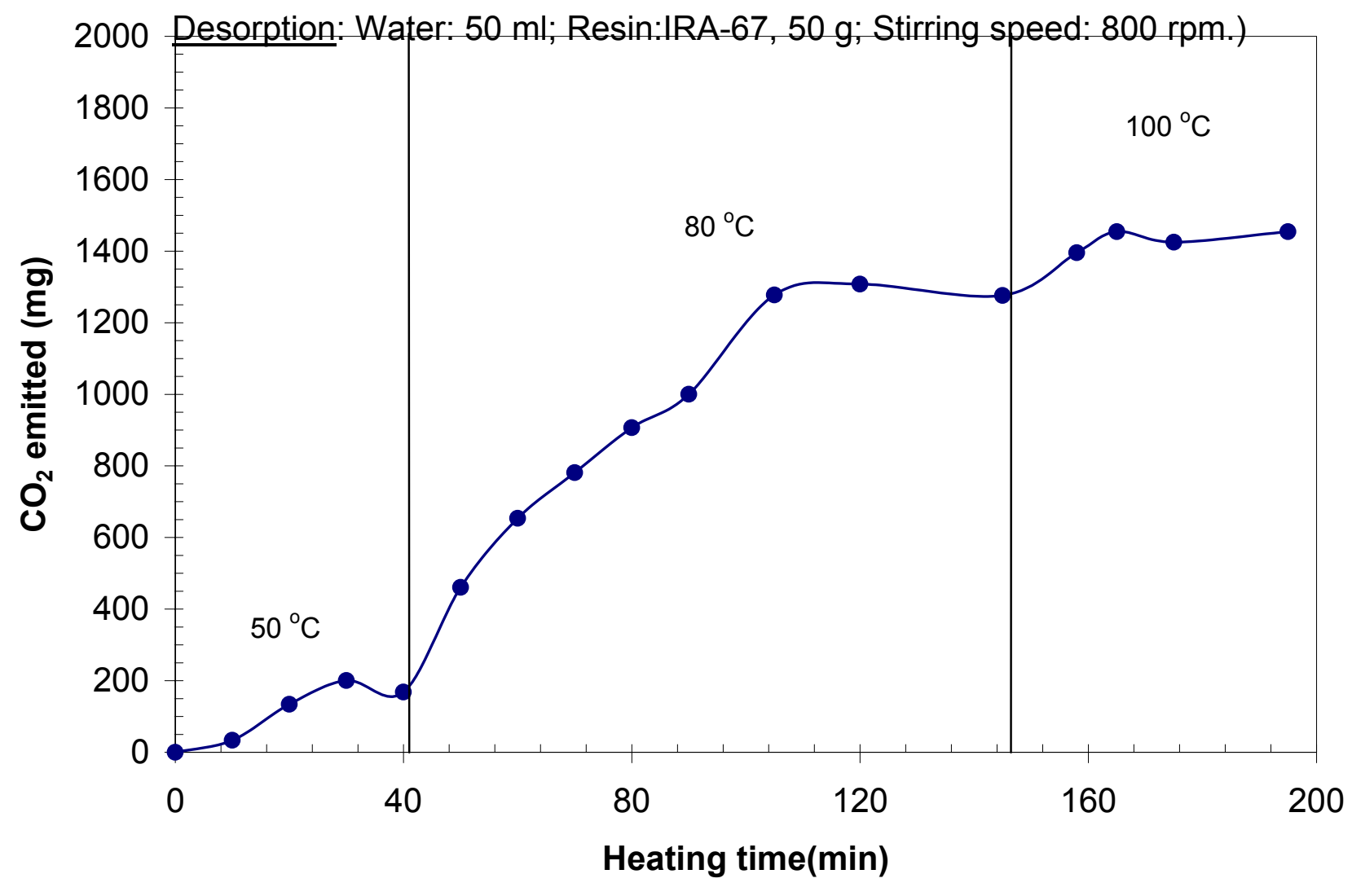


Figure 6. Influence of ratio of resin to water volume on desorption of resin (Adsorption: $\mathrm{NH}_{4} \mathrm{HCO}_{3}: 50 \mathrm{ml}, 1 \mathrm{M}$; Resin: IRA-67, $50 \mathrm{~g}$; Stirring speed: $800 \mathrm{rpm}$.; Temp.: $25^{\circ} \mathrm{C}$ Desorption: Resin: IRA-67, $50 \mathrm{~g}$; Stirring speed: 800 rpm.; Temp.: $100^{\circ} \mathrm{C}$ )

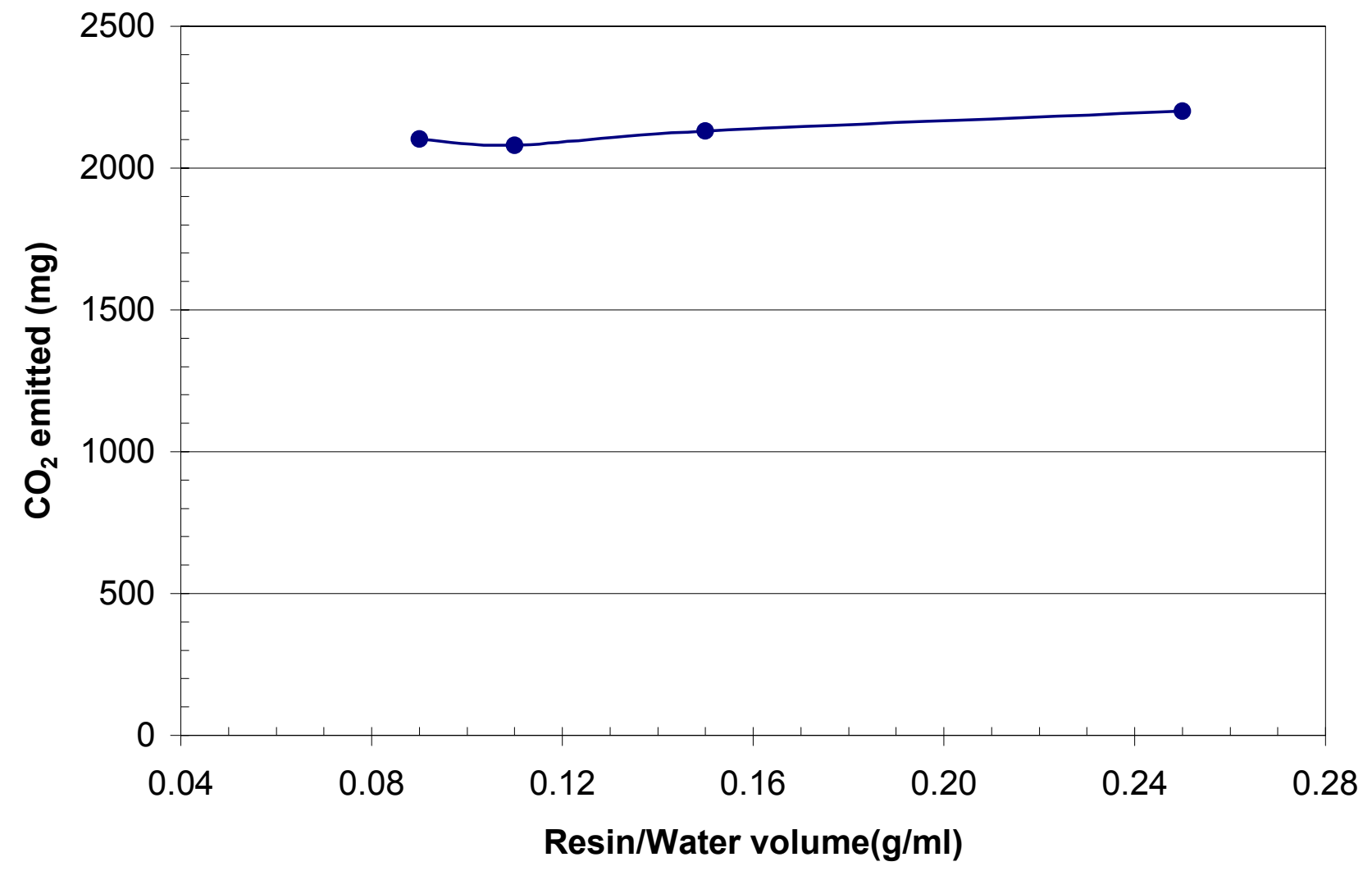


Figure 7. Sustainability of resin for regeneration of ammonia (Adsorption: $\mathrm{NH}_{4} \mathrm{HCO}_{3}$ solution: $200 \mathrm{ml}, 1 \mathrm{M}$; Resin: IRA-67, $50 \mathrm{~g}$; Stirring speed: $800 \mathrm{rpm}$; Temp.: $25^{\circ} \mathrm{C}$ Desorption: Water: $200 \mathrm{ml}$; Resin: IRA-67: 50 g; Stirring speed: 800 rpm.; Boiling 1 hr.;)

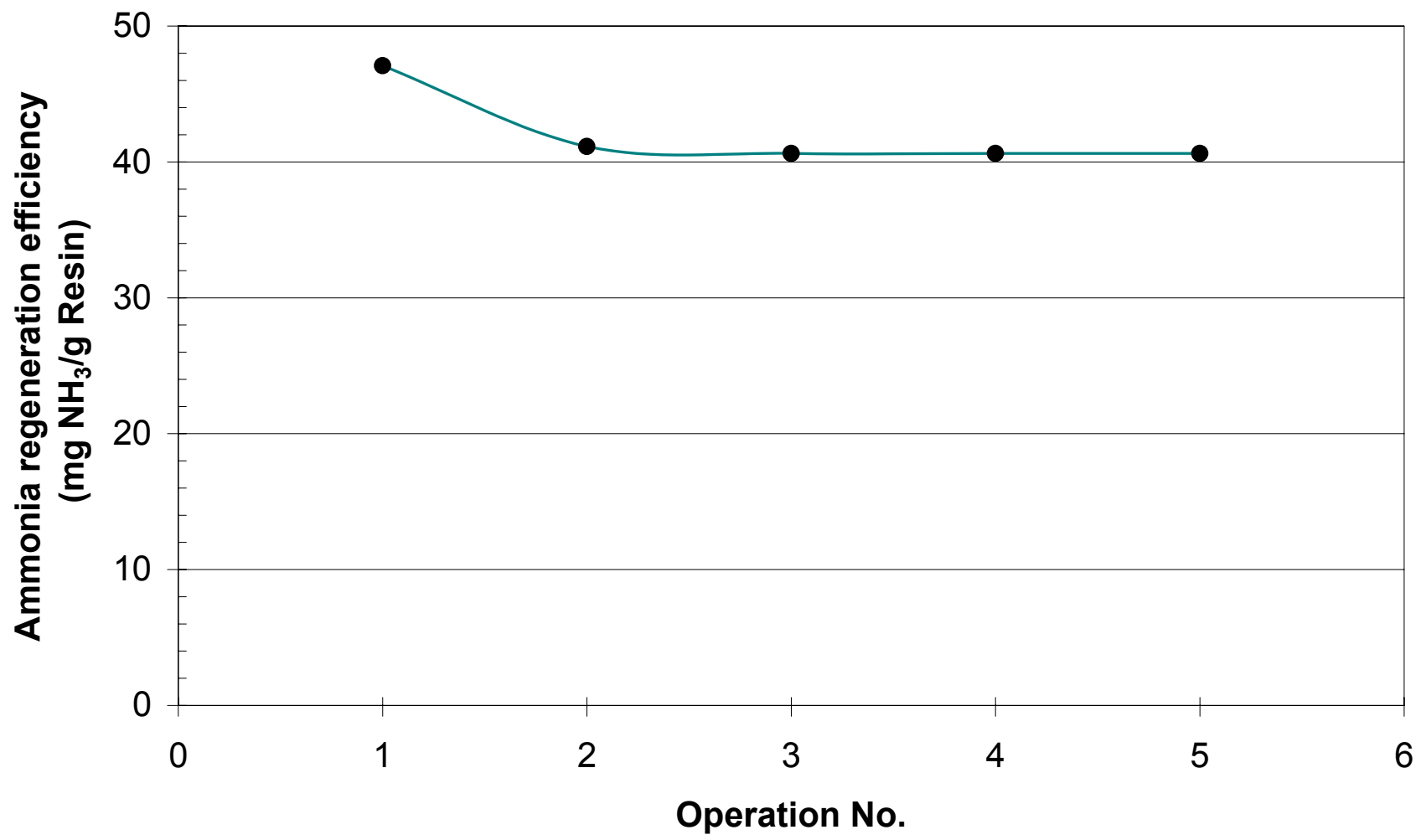

